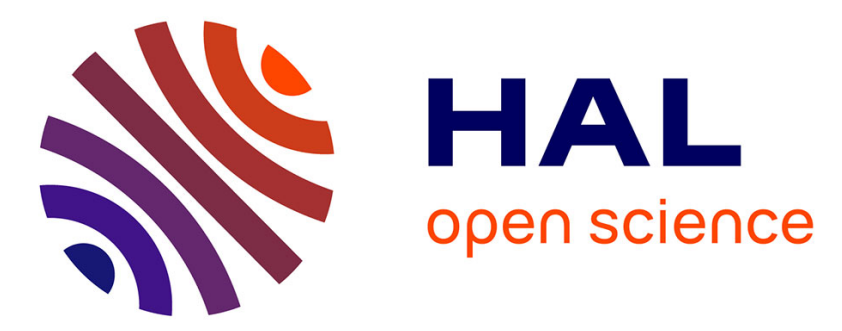

\title{
Catalyst-free soft-template synthesis of ordered mesoporous carbon tailored using phloroglucinol/ glyoxylic acid environmentally friendly precursors
}

Camelia Ghimbeu, Loïc Vidal, Luc Delmotte, Jean-Marc Le Meins, Cathie Vix-Guterl

\section{To cite this version:}

Camelia Ghimbeu, Loïc Vidal, Luc Delmotte, Jean-Marc Le Meins, Cathie Vix-Guterl. Catalystfree soft-template synthesis of ordered mesoporous carbon tailored using phloroglucinol/ glyoxylic acid environmentally friendly precursors. Green Chemistry, 2014, 16 (6), pp.3079-3088. $10.1039 / \mathrm{c} 4 \mathrm{gc} 00269 \mathrm{e}$. hal-02272625

\section{HAL Id: hal-02272625 \\ https://hal.science/hal-02272625}

Submitted on 7 Feb 2020

HAL is a multi-disciplinary open access archive for the deposit and dissemination of scientific research documents, whether they are published or not. The documents may come from teaching and research institutions in France or abroad, or from public or private research centers.
L'archive ouverte pluridisciplinaire HAL, est destinée au dépôt et à la diffusion de documents scientifiques de niveau recherche, publiés ou non, émanant des établissements d'enseignement et de recherche français ou étrangers, des laboratoires publics ou privés. 


\title{
Catalyst-free soft-template synthesis of ordered mesoporous carbon tailored using phloroglucinol/ glyoxylic acid environmentally friendly precursors $\uparrow$
}

\author{
Camelia Matei Ghimbeu, Loïc Vidal, Luc Delmotte, Jean-Marc Le Meins and \\ Cathie Vix-Guterl
}

\begin{abstract}
Carbon porous materials with a periodically ordered pore structure, controlled pore size and geometry and high thermal stability are synthesized using self-assembly of environmentally friendly phloroglucinol/ glyoxylic acid precursors with an amphiphilic triblock copolymer template. Glyoxylic acid, a plant-derived compound, is used for the first time as a substituent of carcinogen formaldehyde usually employed in such a synthesis. Thanks to the double functionality, i.e., aldehyde and carboxylic acid, glyoxylic acid plays not only the role of a cross-linker for the formation of the resin but also the role of a catalyst by creation of $\mathrm{H}$-bonding or specific reactions between the precursors. Hence, no extra catalyst such as strong acids $(\mathrm{HCl})$ or bases $(\mathrm{NaOH})$ is any longer required. Carbon films and powders were successfully prepared with high surface areas (up to $800 \mathrm{~m}^{2} \mathrm{~g}^{-1}$ ), high porous volume (up to $1 \mathrm{~cm}^{3} \mathrm{~g}^{-1}$ ), tunable pore size $(0.6 \mathrm{~nm}$ to $7 \mathrm{~nm}$ ) and various pore architectures (hexagonal, cubic, and ink-bottle) by tuning the precursor ratio and by applying different manufacturing engineering strategies. Insights on the synthesis mechanism of the phenolic resin and carbon mesostructures were obtained using several analysis techniques, i.e., nuclear magnetic resonance $\left({ }^{13} \mathrm{C} N M R\right)$ and FTIR spectroscopy, temperature programmed desorption coupled with mass spectrometry (TPD-MS) and thermo-gravimetric analysis (TGA).
\end{abstract}

\section{Introduction}

Since their discovery, ${ }^{1-3}$ ordered carbon materials have attracted tremendous attention due to their outstanding properties including a high surface area, uniform and interconnected pores, tunable pore size and shape, good electronic conductivity and chemical inertness. ${ }^{4-7}$ Undoubtedly, these features make them ubiquitous and indispensable for a wide range of applications in the field of catalysis, ${ }^{8}$ energy conversion and storage, ${ }^{7,9}$ sensors, ${ }^{10}$ adsorption and separation, ${ }^{11,12}$ controlled drug release, ${ }^{13,14}$ etc. Moreover, the ordered carbons can be also considered as model materials for establishing a comprehensive understanding of physical-chemical phenomena occurring during the applications. ${ }^{4,9,10,15,16}$ The design of such interesting materials was first achieved by the so-called hard-template or nanocasting approach. ${ }^{1-3}$ In this approach, an ordered inert template (zeolite, silica) is infiltrated with a carbon precursor (propylene, sucrose, furfuryl alcohol, etc.), followed by confined carbonization and then removal of the template by harsh acidic or basic conditions ( $\mathrm{HF}, \mathrm{NaOH}$ ). Despite the large variety of ordered carbon materials that can be obtained, ${ }^{4,6,17}$ this multistep, expensive and hazardous pathway limits to some extent its large scale utilization. To overcome these drawbacks, more recently, ${ }^{18-21}$ the softtemplate approach has been developed and has received much greater attention due to the limited synthesis steps, easy production of large quantities ${ }^{22}$ and moreover the possibility of designing various kinds of carbon materials such as films, powders and monoliths. ${ }^{5,6}$

Generally this method is based on the self-assembling of carbon precursors with a soft block copolymer via hydrogen bonding and/or covalent bonding under basic or acidic conditions. ${ }^{5,18}$ A further thermopolymerization $\left(\sim 100^{\circ} \mathrm{C}\right)$ and carbonization and/or graphitization step $\left(600-2500^{\circ} \mathrm{C}\right)$ allows the obtainment of ordered carbon structures. The most commonly employed phenolic monomers are phenol, resorcinol and phloroglucinol, and are used in most cases together with formaldehyde as a cross-linker. The latter one is well known to be a carcinogen which represents an important drawback. It is worth mentioning that very little recent effort has been made by our group ${ }^{23}$ or other groups ${ }^{24,25}$ to overcome this major 
problem. However, even if more environmental precursors were explored (tannin, fructose, etc.), high acidic conditions and high temperatures and pressures were still required to obtain the ordered carbons. These parameters are well known to affect the reactivity, the polymerization rate, the self-assembly process and finally the carbon features. In addition, they have a direct negative impact from the environmental point of view and for industrial applications where non-corrosive reagents and low cost procedures are strongly required. The necessity to find other catalysts than the commonly used $\mathrm{NaOH}$ and $\mathrm{HCl}$ was recently pointed out in a recent review devoted to the synthesis of ordered mesoporous carbon by the soft-template approach. ${ }^{5}$

In the present work, we propose as an alternative to the already existing precursors and catalysts the environmental friendly glyoxylic acid, which thanks to its bi-functionality (aldehyde and carboxylic acid groups) plays a double role in carbon synthesis, i.e., as a cross-linker for the formation of phenolic resin and as a catalyst as it can promote polymerization of phenolic resin. This compound is a colorless solid that occurs as a natural constituent of plants and its release in air, water and soil is biodegradable which makes it very attractive.

Therefore, we report in this work a green, simple and efficient approach for the synthesis of ordered carbon materials by means of self-assembly of environmentally friendly phloroglucinol/glyoxylic acid carbon precursors and a structure directing agent at room temperature and without a catalyst. The phenolic resol solution obtained with these precursors is suitable for the synthesis of ordered carbon films as well as carbon powders by both evaporation induced selfassembly (EISA) and macroscopic phase separation routes. ${ }^{5}$ The proposed green precursors allow obtaining ordered carbon materials with tunable textural characteristics (surface area, pore size, pore geometries) and high thermal stability by simply adjusting the molar ratio between the precursors as highlighted by several analysis techniques.

\section{Materials and methods}

\subsection{Chemicals}

Triblock copolymer Pluronic F127 (poly(ethylene oxide)-blockpoly(propylene oxide)-block-poly(ethylene oxide, $\mathrm{PEO}_{106} \mathrm{PPO}_{70^{-}}$ $\left.\mathrm{PEO}_{106}, M_{\mathrm{w}}=12600 \mathrm{Da}\right)$, phloroglucinol (1,3,5-benzentriol, $\left.\mathrm{C}_{6} \mathrm{H}_{6} \mathrm{O}_{3}\right)$, glyoxylic acid monohydrate $\left(\mathrm{C}_{2} \mathrm{H}_{2} \mathrm{O}_{3} \cdot \mathrm{H}_{2} \mathrm{O}\right)$ and absolute ethanol $\left(\mathrm{C}_{2} \mathrm{H}_{6} \mathrm{O}\right)$ were purchased from Sigma-Aldrich and used as received without any further purification.

\subsection{Synthesis}

The carbon materials were synthesized by the evaporationinduced self-assembly pathway and macroscopic phase separation.

Powders by EISA. In a typical EISA synthesis, phloroglucinol $(0.82 \mathrm{~g})$, glyoxylic acid monohydrate $(0.61 \mathrm{~g})$ and Pluronic F127 $(1.61 \mathrm{~g})$ were dissolved under stirring at room temperature in
Table 1 Synthesis conditions used for the preparation of carbon materials

\begin{tabular}{llll}
\hline $\begin{array}{l}\text { Material } \\
\text { name }\end{array}$ & Method & $\begin{array}{l}\text { Molar ratio of } \\
\text { phloroglucinol } \\
\text { glyoxylic acid }\end{array}$ & $\begin{array}{l}\text { Mass ratio of } \\
\text { phloroglucinol }+ \\
\text { glyoxylic acid : template }\end{array}$ \\
\hline CGY-1S & EISA & $1: 1$ & $1: 0.6$ \\
CGY-1 & EISA & $1: 1$ & $1: 1.2$ \\
CGY-1.25 & EISA & $1: 1.25$ & $1: 1.1$ \\
CGY-1.5 & EISA & $1: 1.5$ & $1: 0.9$ \\
CGY-1P & Phase separation & $1: 1$ & $1: 1.2$
\end{tabular}

absolute ethanol $(40 \mathrm{ml})$. The obtained clear solution was transferred into smooth glass dishes and left at room temperature for about 6 hours in order to evaporate the ethanol solution, and subsequently a thermal treatment at $80{ }^{\circ} \mathrm{C}$ for one night was performed to cross-link the phenolic resin framework in the material. The obtained materials were scraped from the dishes and pyrolysed at $600{ }^{\circ} \mathrm{C}$ under inert atmosphere (Ar) for 2 hours. The influence of glyoxylic acid amount in the reaction mixture was studied by varying its quantity while keeping the other parameters constant. Thus, different molar ratios between phloroglucinol and glyoxylic acid (1:1; $1: 1.25$ and $1: 1.5$ ) were defined (see Table 1 ).

The obtained materials are denoted CGY- $x$, where $x$ denotes the molar ratio of phloroglucinol/glyoxylic acid (CGY-1, CGY-1.25 and CGY-1.5). The influence of surfactant on the CGY-1 material was studied by decreasing the amount of template (sample CGY-1S, where $\mathrm{S}$ means surfactant, Table 1).

Films by EISA. Thin films were also prepared by dip-coating on a quartz plane substrate. The substrate was first cleaned with ethanol and acetone and after drying was immersed five times in the solution with a speed of $1.2 \mathrm{~mm} \mathrm{~s}^{-1}$, a distance of $30 \mathrm{~mm}$ and an immersion time of $10 \mathrm{~s}$. Drying, curing and carbonization were performed as described before.

Powders by phase separation. Carbon powders were also obtained by phase separation which occurs after a certain time period, typically between 1.5 and 5 days of aging the solution at room temperature. The required time to achieve the phase separation depends on the molar ratio between phloroglucinol and glyoxylic acid. Once the phase separation occurred, the upper layer solution was discarded while the rich polymer-gel was recovered and then dried, thermopolymerized and pyrolysed in a similar way as already mentioned. The obtained sample is denoted CGY-1P (P meaning powder).

\subsection{Characterisation}

Carbon material characterization. The textural properties of the materials were investigated with a Micromeritics ASAP 2020 instrument using $\mathrm{N}_{2}$ adsorbate at $-196{ }^{\circ} \mathrm{C}$. Prior to the analysis, the samples were out-gassed overnight in a vacuum at $300{ }^{\circ} \mathrm{C}$ on the degassing port followed by $4 \mathrm{~h}$ out-gassing on the analyse port. The BET (Brunauer-Emmett-Teller) surface 
area $\left(S_{\mathrm{BET}}\right)$ was calculated from the linear plot in the relative pressure range of $0.05-0.3$ while the micropore volume $\left(V_{\text {micro }}\right)$ was determined using the Dubinin-Radushkevich (DR) equation. The mesopore volume $\left(V_{\text {meso }}\right)$ was obtained by subtracting the micropore volume from the total pore volume of $\mathrm{N}_{2}$ adsorbed at a relative pressure $P / P_{0}$ of 0.95 . The average mesopore size was determined with the BJH (Barrett-JoynerHalenda) model on the adsorption branch. The micropore size distribution was determined using the $\mathrm{N}_{2}$ DFT model for slit pores.

X-Ray powder diffraction (XRD) data were collected with a

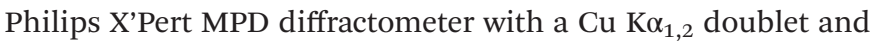
a flat-plate Bragg-Brentano theta-theta geometry.

The long-range ordering of the materials was studied by small angle X-Ray scattering (SAXS) analysis using a Rigaku SMax 3000 equipped with a rotating $\mathrm{Cu}$ anode Micromax$007 \mathrm{HF}(40 \mathrm{kV}, 30 \mathrm{~mA})$ and OSMIC CMF optics. Image ${ }^{26}$ software was used for SAXS treatment of different images collected with the X-ray $2 \mathrm{D}$ detector. The unit cell parameter, $a_{0}$, was calculated using the formulas $2 d_{100} / \sqrt{ } 3$ for hexagonal structures and $(\sqrt{ } 2) d_{110}$ for cubic structures, respectively, ${ }^{27}$ where $d_{100}$ and $d_{110}$ represent the $d$ spacing values of the 100 and 110 diffraction planes.

The carbon material morphology was evaluated by transmission electron microscopy (TEM) with a Philips CM200 instrument working at $200 \mathrm{kV}$. For film analysis a small quantity was mechanically removed from the substrate.

Phenolic resin characterization. A JASCO Fourier transform infrared spectrometer 4100 was used to characterize the chemical surface of the phenolic resin before carbonization. First, a background spectrum was run, and then the spectra of the phenolic resin samples were collected against the background spectrum. A total of 60 scans at a resolution of $16 \mathrm{~cm}^{-1}$ (in the IR region of $4000-600 \mathrm{~cm}^{-1}$ ) were performed to achieve a good signal-to-noise ratio.

Proton and ${ }^{13} \mathrm{C}$ solid-state CPMAS NMR experiments have been performed on a Bruker Avance $750 \mathrm{MHz}$ spectrometer using $3.2 \mathrm{~mm}$ zirconia rotors spinning at a MAS frequency of $18 \mathrm{kHz}$.

Recycle delay for all CP experiments was $4 \mathrm{~s}$ and spinal-64 decoupling was applied during signal acquisition. Cross-polarization transfers were performed using adiabatic tangential ramps to enhance the transfer efficiency, and the contact time was $1 \mathrm{~ms}$. Single-pulse MAS experiments were used for ${ }^{1} \mathrm{H}$ spectra.

Thermo-gravimetric analysis (TGA) was used to study the mass loss during phenolic resin carbonization by heating with $2{ }^{\circ} \mathrm{C} \min ^{-1}$ up to $950{ }^{\circ} \mathrm{C}$ under nitrogen (METTLER-TOLEDO TGA 851e). The type of species evolved during the carbonization of phenolic resin was analyzed by temperature programmed desorption coupled with mass spectrometry. ${ }^{28,29} \mathrm{~A}$ small quantity of cured phenolic resin/F127 ( 2 mg) was introduced into a quartz tube place inside a furnace and heattreated in a vacuum with a linear heating rate of $2^{\circ} \mathrm{C} \mathrm{min}^{-1}$ up to $950{ }^{\circ} \mathrm{C}$. The gases evolved during the heating process were continuously detected using a mass spectrometer.

\section{Results and discussion}

\subsection{Carbon characterization}

The nitrogen adsorption/desorption isotherms of carbon materials synthesized using different mass ratios between the precursors (see Table 1) are shown in Fig. 1a. For CGY-1S and CGY-1 the mass ratio between the carbon precursors (phloroglucinol-glyoxylic acid) and the template is 0.6 and 1.2, respectively. The two carbons exhibit a type IV isotherm characteristic of mesoporous materials. A high increase of nitrogen uptake in the low relative pressure $\left(P / P_{0}\right)$ region corresponds to the volume adsorbed by micropores and the formation of nitrogen multilayers on the pore walls. This adsorbed volume is higher in the case of CGY-1, maybe due to the higher quantity of Pluronic which by decomposition favors, besides mesopore formation, also the creation of micropores. The DFT micropore size distribution (Fig. S1†) reveals for all materials pores with average diameter $0.6 \mathrm{~nm}$ but also some pores with higher diameter $(\sim 1.2 \mathrm{~nm})$.

Moreover, in both cases a hysteresis loop of $\mathrm{H}_{2}$-type (CGY-1S) or $\mathrm{H}_{1}$-type (CGY-1) is observed, respectively, when the mass ratio between the precursors and the template is increased from 0.6 to $1.2 . \mathrm{H}_{2}$ hysteresis indicates a delayed condensation and in addition pore blocking percolation or cavitation effects are present. ${ }^{30-32}$ This type of hysteresis is specific to materials having complex pore structure, namely ink-bottle or cage-like pores.

The lower limit of the closure of the hysteresis loop occurs at a relative pressure comprised between 0.45 and 0.48 , which suggests a cavitation mechanism ${ }^{30-32}$ with pore entrance diameter to the main mesoporous cavities less than $6 \mathrm{~nm}$. H1-like hysteresis is usually attributed to uniform mesopores with a cylindrical geometry. Therefore, the difference in the features of the hysteresis loops can be correlated to different pore topologies. The average pore size of CGY-1S and CGY-1 is $8.3 \mathrm{~nm}$ and $6.5 \mathrm{~nm}$, respectively (Table 2). Particularly in the
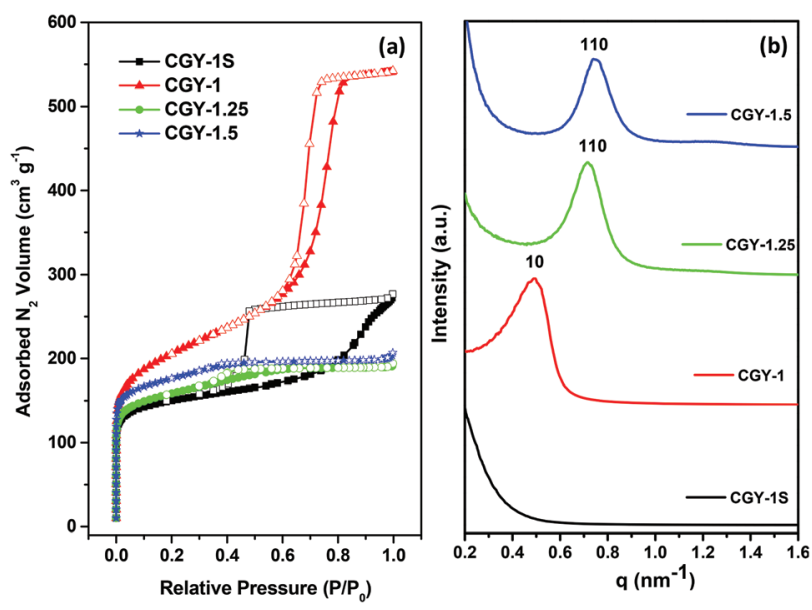

Fig. 1 Nitrogen adsorption/desorption isotherms (a) and SAXS patterns (b) of carbon materials synthesized using different experimental conditions as listed in Table 1. 
Table 2 Textural and structural properties of carbon materials synthesized under different conditions

\begin{tabular}{llllllll}
\hline $\begin{array}{l}\text { Material } \\
\text { name }\end{array}$ & $\begin{array}{l}S_{\text {BET }} \\
\left(\mathrm{m}^{2} \mathrm{~g}^{-1}\right)\end{array}$ & $\begin{array}{l}V_{\mathrm{t}} \\
\left(\mathrm{cm}^{3} \mathrm{~g}^{-1}\right)\end{array}$ & $\begin{array}{l}V_{\text {micro }} \\
\left(\mathrm{cm}^{3} \mathrm{~g}^{-1}\right)\end{array}$ & $\begin{array}{l}V_{\text {meso }} \\
\left(\mathrm{cm}^{3} \mathrm{~g}^{-1}\right)\end{array}$ & $\begin{array}{l}D_{\mathrm{p}} \\
(\mathrm{nm})\end{array}$ & $\begin{array}{l}a_{0} \\
(\mathrm{~nm})\end{array}$ & $\begin{array}{l}t_{\text {wall }} \\
(\mathrm{nm})\end{array}$ \\
\hline CGY-1S & 493 & 0.40 & 0.23 & 0.17 & 8.3 & - & - \\
CGY-1 & 679 & 0.83 & 0.34 & 0.49 & 6.5 & 15.8 & 9.3 \\
CGY-1.25 & 525 & 0.30 & 0.24 & 0.06 & 2.9 & 12.4 & 8.2 \\
CGY-1.5 & 582 & 0.31 & 0.27 & 0.04 & 2.7 & 12.0 & 8.0
\end{tabular}

$S_{\mathrm{BET}}$ - the total surface area determined by the BET method. $V_{\mathrm{T}}, V_{\text {meso }}$ and $V_{\text {micro }}$ - the total pore volume, mesopore volume and micropore volume. $D_{\mathrm{P}}$ - mesopore diameter calculated by the $\mathrm{BJH}$ method from the isotherm adsorption branch. $a_{0}$ - unit cell parameter calculated by SAXS. $t_{\text {wall }}$ - the wall thickness is calculated using the equation $a_{0}-D_{\mathrm{P}}$ for hexagonal structure and $[(\sqrt{ } 3 / 2)](a-D)$ for cubic structure. ${ }^{27,33}$
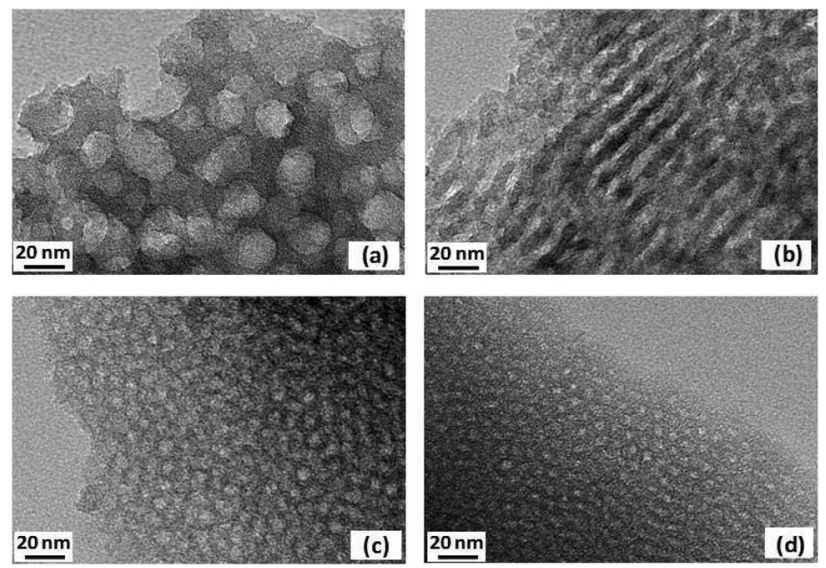

Fig. 2 TEM pictures of CGY-1S (a), CGY-1 (b), CGY-1.25 (c) and CGY-1.5 (d) carbon materials obtained using different experimental conditions (Table 1).

case of CGY-1S the pore size determined by the BJH adsorption is underestimated by about $45 \%$, in good agreement with previous reports for this type of complex pore morphology. ${ }^{34}$ This can be sustained by the TEM pictures (Fig. 2a) showing pores with an average size of about $14 \mathrm{~nm}$ as determined by ImageJ software. The surface area and the total pore volume (Table 2) are higher for the CGY-1 $\left(679 \mathrm{~m}^{2} \mathrm{~g}^{-1}\right.$ and $\left.0.83 \mathrm{~cm}^{3} \mathrm{~g}^{-1}\right)$ compared to CGY-1S material $\left(493 \mathrm{~m}^{2} \mathrm{~g}^{-1}\right.$ and $\left.0.4 \mathrm{~cm}^{3} \mathrm{~g}^{-1}\right)$.

The influence of glyoxylic acid amount on the carbon textural properties was also studied. With increasing the quantity of glyoxylic acid (CGY-1.25 and CGY-1.5) the obtained material still exhibits an isotherm of type IV but the hysteresis is no longer visible. Previous studies have shown the absence of a hysteresis loop for pore sizes in the range of small mesopores. ${ }^{35}$ The surface area and the total porous volume decrease with the increase of the glyoxylic acid amount. A significant decrease in the mesoporous volume can be noticed which is accompanied by a decrease in the pore size from $7.3 \mathrm{~nm}$ (for CGY-1) to 2.9 and $2.7 \mathrm{~nm}$ for CGY-1.25 and CGY-1.5, respectively.

The SAXS patterns from Fig. 1b show no diffraction peak for CGY-1S indicating no ordering at long range distances. For all the other materials, the SAXS patterns reveal one resolved peak. For CGY-1 the peak is placed at $q \sim 0.5 \mathrm{~nm}^{-1}$ and can be indexed to the 10 diffraction planes of an ordered 2D hexagonal $\mathrm{p} 6 \mathrm{~m}$ mesostructure. ${ }^{27,33}$

In the case of CGY-1.25 and CGY-1.5 the SAXS maximum peak position is shifted towards higher $q$ values $\sim 0.7$ and $0.75 \mathrm{~nm}^{-1}$, respectively, corresponding to the 110 diffraction planes of an ordered body-centered cubic mesostructure with a space group $\operatorname{Im} \overline{3} m$. $^{27,33}$

The values of the cell lattice parameter, $a_{0}$ (Table 2), calculated from the SAXS parameters are $15.8 \mathrm{~nm}$ for CGY-1 material and 12.4 $\mathrm{nm}$ and $12.0 \mathrm{~nm}$ for CGY-1.25 and CGY-1.5 carbons, respectively. Hence, a shrinkage in the carbon framework is noticed besides the mesostructure pore structure modification when the molar ratio between glyoxylic acid and phloroglucinol increases in the reaction mixture from 1 to 1.25 . Further increase in this ratio to 1.5 or 2 (data not shown) does not induce significant morphology or structure modifications.

The wall thickness calculated based on the SAXS peak position and textural parameters is listed in Table 2. The wall thickness decreases from $9.3 \mathrm{~nm}$ (CGY-1) to $8.0 \mathrm{~nm}$ (CGY-1.5) when decreasing the ratio of $\mathrm{F} 127 /$ resin from 1.2 to 0.9 . This is not surprising since the wall thickness is related to the domain sizes of phenolic resins structured by the soft-templates and the ratio of $\mathrm{F} 127$ templates to phenolic resin. ${ }^{33}$

The morphology of the carbons was studied by TEM. As depicted in Fig. 2a, the CGY-1S carbon presents spherical mesopores with average size of about $14 \mathrm{~nm}$. When increasing the quantity of Pluronic (CGY-1, Fig. 2b) the material presents stripe-like and parallel channels specific to a 2D hexagonal structure in good agreement with the SAXS results. When, in addition, the glyoxylic acid amount increases (CGY-1.25 and CGY-1.5) the materials exhibit ordered cubic mesopores interconnected through smaller windows. The 2D and 3D interconnected porosity makes these materials interesting for a wide range of potential applications, i.e., separation, sensing, energy storage and catalysis.

It is worth mentioning that besides the synthesis of powder by the EISA method, thin films can also be obtained by this method using a simple dip-coating method which is suitable for large surface coatings as well. A typical film cast on a quartz substrate is shown in Fig. 3a together with its morphology. We can observe, by TEM pictures, spherical pores oriented perpendicular to the substrate (Fig. 3a). The mesoporous film is continuous over a large domain without visible cracks, and its thickness evaluated by AFM was found to be around $120 \mathrm{~nm}$.

The average centre-to-centre distance between the two adjacent mesochannels is about $16 \mathrm{~nm}$ while the pore size is roughly estimated at $11 \mathrm{~nm}$. As can be noticed, the morphology of the film is not the same as that of the powder (Fig. 3b) even if identical chemical conditions were used. Changes in the material structure induced by the experimental casting procedure, i.e., powders or thin films, were already reported and very nicely described by Song et al. ${ }^{36}$ 

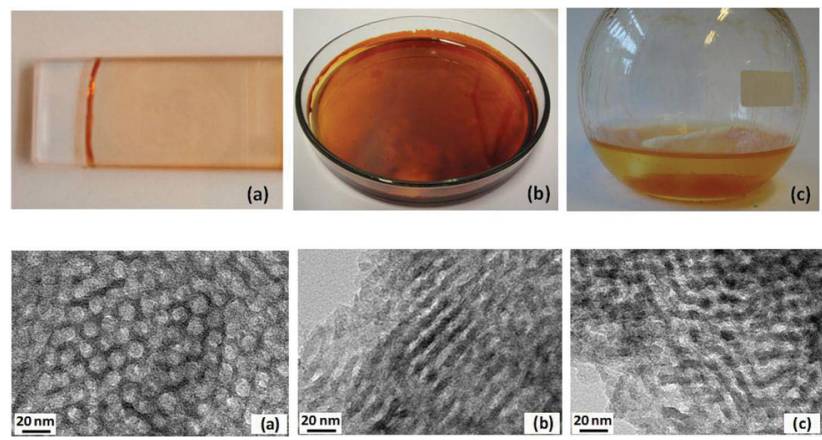

Fig. 3 (bottom) TEM pictures of carbon (a), EISA thin films (b), EISA powders (CGY-1) and (c) powders by phase separation (CGY-1P); (top) the corresponding phenolic resin before thermal treatment. The molar ratio between the precursors corresponds to that of CGY-1 carbon (Table 1).

This can be explained by the fact that in the case of films, its interfaces impose geometric constraints of self-assembly which are absent in bulk powder.

The powders obtained by EISA (CGY-1, Fig. 3b) were compared with those obtained by the phase separation method (CGY-1P, Fig. 3c). The advantage of the phase separation method is mainly related to the higher quantity that can be synthesized than that reported for the EISA method. Typically, for the precursor solution volume used in this work $(40 \mathrm{ml})$ about $0.5 \mathrm{~g}$ of carbon is obtained. This quantity can be easily scaled-up using bigger size synthesis flasks. It should be mentioned that by this method the complete phase separation occurs in about 5 days for CGY-1P (Fig. 3c, up) and this time decreases as the glyoxylic acid quantity increases (one day for phloroglucinol: glyoxylic acid molar ratio, $1: 2$ ). The reaction is slow mainly due to the mild $\mathrm{pH}$ synthesis conditions employed $(\sim 5)$ and the absence of a catalyst.

It should be remarked that these carbon powders present quite a similar morphology but are less ordered for the second synthesis method (Fig. 3b and c). The textural properties are also slightly different (Fig. S2 and Table S1, ESI $\dagger$ ), the CGY-1 having higher surface area and porous volume, and a narrower and more defined pore size than the CGY-1P. Moreover, it can be mentioned that the morphology and the structure of the powders obtained by tuning the molar ratio between the precursors may differ from those obtained by the EISA method (data not shown). This can be related to the different self-assembly mechanism when these two different approaches are used. The evaporation induced self-assembly involves the self-assembly of phloroglucinol/glyoxylic acid phenolic resins (resols) with the triblock polymer through organic-organic interactions occurring during the evaporation of the solvent.

This method is very suitable for the synthesis of carbon films and monoliths but, however, for the synthesis of large powder quantities the macroscopic phase separation approach is more convenient. Contrary to the EISA method, in the phase separation approach the self-assembly of resols around the
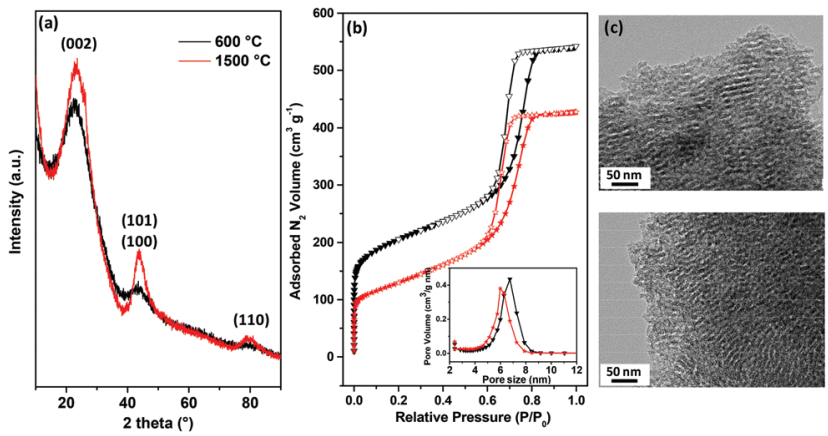

Fig. 4 XRD patterns (a), nitrogen adsorption/desorption isotherms (b) (inset: pore size distribution) and TEM pictures (c) of CGY-1 carbon heat treated at $600{ }^{\circ} \mathrm{C}$ and subsequently at $1500{ }^{\circ} \mathrm{C}$ (CGY-1T).

template with the formation of ordered mesostructures occurs via a macroscopic phase separation. Firstly, the triblock copolymer self-assembles in micelles and the carbon precursor (phloroglucinol) interacts with the PEO block of the template via hydrogen or columbic interactions to form a self-assembly structure, while glyoxylic acid cross-links with phloroglucinol and a phase separation containing a rich polymer phase and a liquid solvent occurs. Further separation and isolation of this rich polymer phase followed by thermopolymerization and carbonization gives the ordered carbon powders ${ }^{5,37}$.

The thermal stability of ordered carbon materials is an important issue for designing materials for various applications where graphitic carbons possessing good conductivity and controlled textural properties (high surface area and controlled pore size) are required. The structure of the as-synthesized carbon materials at $80{ }^{\circ} \mathrm{C}$ was investigated by the XRD technique (Fig. S3, ESI $\dagger$ and Fig. $4 \mathrm{a}-\mathrm{c}$ ) and the influence of further thermal annealing at higher temperature $\left(380{ }^{\circ} \mathrm{C}\right.$, $600{ }^{\circ} \mathrm{C}$ and $1500{ }^{\circ} \mathrm{C}$ ) on the structural and textural properties was evaluated. At $80{ }^{\circ} \mathrm{C}$ (Fig. S3, ESI $\dagger$ ) the XRD patterns are characterized mainly by one peak placed around $\sim 23^{\circ}$ which corresponds to the (002) reflection of graphite. The peak is very broad suggesting a material with a low degree of graphitization. A second less intense peak appears at $\sim 44^{\circ}$ when the resin is heat treated above $380{ }^{\circ} \mathrm{C}$ (Fig. S3, ESI $\dagger$ and Fig. 4a) which is related to the (101) and/or (100) reflections. When the material is thermally treated at $1500{ }^{\circ} \mathrm{C}$ the (002) and (101) peaks become narrower and sharper and a supplementary small peak $\left(\sim 80^{\circ}\right)$ corresponding to the (110) reflection of a graphitic structure gives indications of the improvement of the graphitization level in the material. At this high temperature the material does not notably modify its textural features (Fig. 4b). The mesoporous volume and the mesopore size remain unchanged while a decrease in the microporous volume is observed (Fig. $4 \mathrm{~b}$ and Table S1, ESI $\dagger$ ). This is also sustained by the TEM pictures (Fig. 4c) showing that the porous morphology and structure organization are conserved. Hence, it is worth highlighting the remarkably high thermal stability of these materials compared to other ordered carbon materials synthesized by the soft-template method under 
neutral or basic conditions where significant structural shrinkage upon treatment was reported along with the modification of textural properties. ${ }^{19,21,38}$

\subsection{Phenolic resin and carbon formation}

Carbon materials are synthesized by self-assembly of phloroglucinol/glyoxylic acid with Pluronic surfactant in ethanol organic medium. The $\mathrm{pH}$ of the solution is around 5 independently of the precursor ratio of phloroglucinol/glyoxylic acid. Due to its double functionality (aldehyde and carboxylic acid) the glyoxilic acid plays an important role in the self-assembly reaction of resol precursors and the triblock copolymer. The aldehyde group induces the cross-linking resulting in the formation of phloroglucinol/glyoxylic acid resol oligomers which further interact with the PEO segments of the self-assembled copolymer block via hydrogen bonding. The carboxyl group was reported to act as a catalyst as it can promote polymerization of phenolic resin by $\mathrm{H}$-bond formation. ${ }^{39,40}$

However, the formation mechanism of mesoporous carbons derived from reosorcinol-formaldehyde resins catalyzed by organic carboxylic acid was not investigated in these reports. In the present work, as glyoxylic acid is used for the first time together with phloroglucinol and in the absence of a catalyst, the phenolic resin and carbon formation mechanism is worth investigating.

Thus, the FT-IR was used to access more details of the chemical surface of phenolic resin synthesized using different quantities of glyoxylic acid. The FT-IR spectra of CGY-1 and CGY-1.5 phenolic resin/F127 composites are shown in Fig. 5.

For both samples, a strong and broad peak is observed around $3450 \mathrm{~cm}^{-1}$ which is related to the $-\mathrm{OH}$ stretching indicating the presence of a large amount of phenolic $-\mathrm{OH}$ groups. The peak placed at $2935 \mathrm{~cm}^{-1}$ along with the peak at $1157 \mathrm{~cm}^{-1}$ correspond to the $\mathrm{C}-\mathrm{H}$ and $\mathrm{C}-\mathrm{O}-\mathrm{C}$ asymmetric stretching vibration of the F127 surfactant. ${ }^{33,41}$ At the same time the band between 2800 and $3000 \mathrm{~cm}^{-1}$ can also corres-

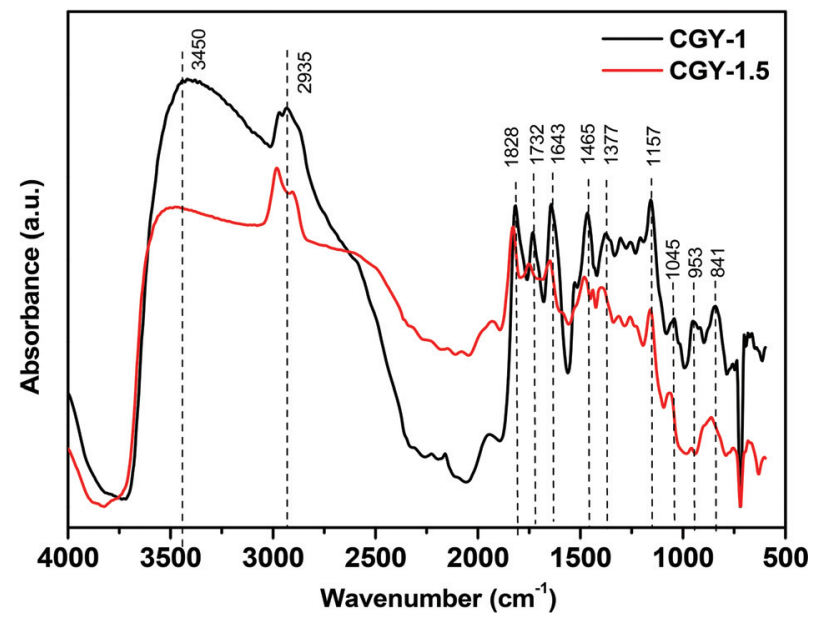

Fig. 5 FT-IR spectra of CGY-1 and CGY-1.5 phenolic resin/F127 cured at $80^{\circ} \mathrm{C}$. pond to the stretching of the $\mathrm{CH}$ saturated bonds of the resin bridges. $^{42}$

Three other peaks are observed between 1900 and $1500 \mathrm{~cm}^{-1}$. The absorption peaks at $1828 \mathrm{~cm}^{-1}$ and $1732 \mathrm{~cm}^{-1}$ are due to the $\mathrm{C}=\mathrm{O}$ groups in cyclic lactones or anhydrides. ${ }^{43}$ The peak seen around $1643 \mathrm{~cm}^{-1}$ is specific to deformation vibration of lattice water. ${ }^{43}$ Several other peaks can also be noticed between 1500 and $1100 \mathrm{~cm}^{-1}$. The peak placed at $1465 \mathrm{~cm}^{-1}$ can be assigned to $\mathrm{C}-\mathrm{H}$ deformation while the peak at $1377 \mathrm{~cm}^{-1}$ belongs to the $\mathrm{OH}$ group in plane in phloroglucinol. ${ }^{44,45}$ The peak from $1045 \mathrm{~cm}^{-1}$ belongs to the single bond $\mathrm{C}-\mathrm{O}$ stretching vibration of resin ester or lactone bridges. ${ }^{42}$

The peaks shown in the interval range $600-900 \mathrm{~cm}^{-1}$ are characteristic of the number of adjacent hydrogen atoms on the aromatic ring, due to the $\mathrm{C}-\mathrm{H}$ vibrations out of the plane of the aromatic ring. The peak from $953 \mathrm{~cm}^{-1}$ is specific to aromatic $=\mathrm{C}-\mathrm{H}$ out-of-plane deformation vibrations in the 1,2,3 trisubstituted benzene ring. ${ }^{43}$ The other peaks placed at 841-849 $\mathrm{cm}^{-1}$ can be related to the $1,2,3,5$ tetrasubstituted benzenes. $^{43}$

Comparing the two phenolic resins IR spectra, the presence of similar vibration bands can be noticed, but the bands are slightly shifted towards higher frequency for CGY-1.5. In addition, it can also be seen that for CGY-1.5 the peak placed at $953 \mathrm{~cm}^{-1}$ is absent.

It should be remembered that this band corresponds to the $=\mathrm{C}-\mathrm{H}$ vibrations in the $1,2,3$ trisubstituted benzene ring, suggesting a different and more advanced cross-linking process in this case where only tetra-substituted benzenes are seen $\left(841 \mathrm{~cm}^{-1}\right.$ peak).

The phenolic resins were also analyzed by ${ }^{13} \mathrm{C}$ and ${ }^{1} \mathrm{H}$ NMR and representative spectra are given in Fig. 6. For ${ }^{13} \mathrm{C} N M R$ spectra several resonances can be noticed. The chemical shifts at $175.1 \mathrm{ppm}$ and $153.3 \mathrm{ppm}$ correspond to the carbon atoms bonded with $\mathrm{O}$ in the carboxylic acid group of glyoxylic acid and unsaturated aromatic $\mathrm{C}$ bonded with $\mathrm{O}$ in phloroglucinol, respectively.

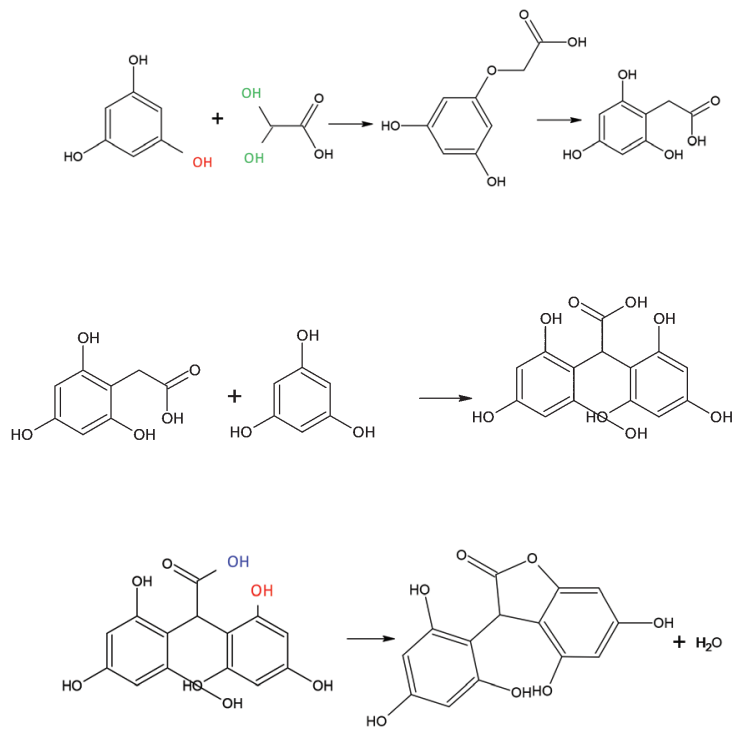



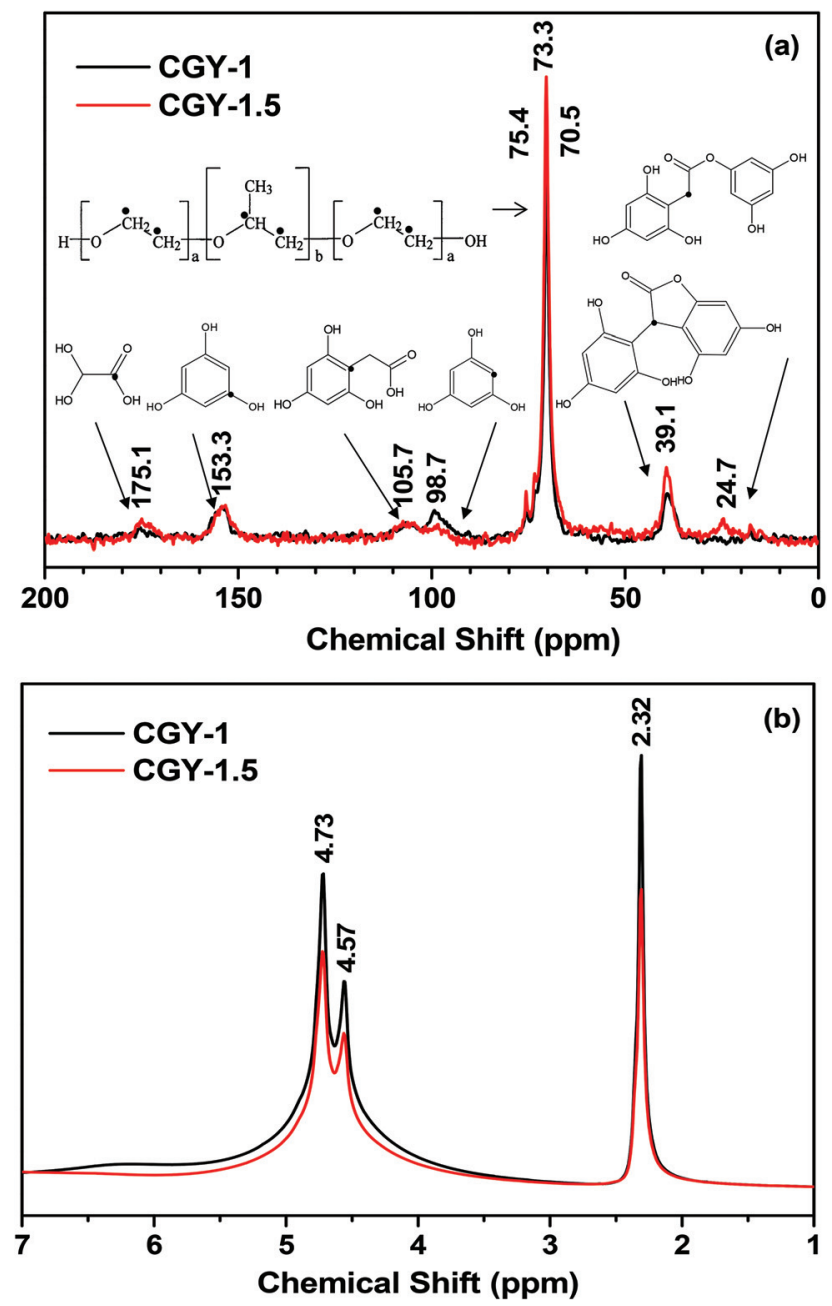

Fig. $6{ }^{13} \mathrm{C}$ and ${ }^{1} \mathrm{H}$ solid-state NMR spectra of CGY-1 and CGY-1.5 phenolic resin/F127 cured at $80^{\circ} \mathrm{C}$.

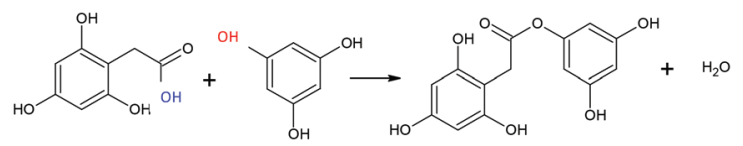

The intensity of the first peak (175.1 ppm) is slightly higher for CGY-1.5 due to the higher quantity of glyoxylic acid in the resin compared to CGY-1 (see Table 1). The $105.7 \mathrm{ppm}$ and 98.7 ppm signals can be related to the unsaturated aromatic carbon bonded with the $\mathrm{C}$ atom in trihydroxy phenylacetic acid and saturated carbon atoms in phloroglucinol, respectively. This indicates the cross-linking of phloroglucinol which is much advanced for CGY-1.5 taking into account the lower intensity of the latest peak compared to CGY-1. The stronger observed chemical shifts around $73.3 \mathrm{ppm}$ are related to the carbon atoms (-CH-; $\left.-\mathrm{CH}_{2}-\right)$ bonded with $\mathrm{O}$ atoms in the triblock copolymer Pluronic F127. ${ }^{27}$

The resonance peak placed at $39.1 \mathrm{ppm}$ can be assigned to the carbon from lactone bridges between the phloroglucinol rings, characteristic of phenolic resins. ${ }^{27,46}$

The much intense peak for the CGY-1.5 resin suggests once again its higher degree of polymerization induced certainly by the greater amount of glyoxylic acid used. In addition to the already observed chemical shifts the CGY-1.5 exhibits an extra peak at $24.7 \mathrm{ppm}$ which is absent for CGY-1 resin. This corresponds to carbon atom bonded to carbon in anhydride or ester bridges suggesting a condensation reaction between two carboxylic groups and/or between a carboxylic group and a hydroxyl group.

Further insights on the chemical structure of these two phenolic resins were obtained by ${ }^{1} \mathrm{H}$ NMR (Fig. 6b). For both samples three NMR signals are noticed at $4.73 \mathrm{ppm}, 4.57 \mathrm{ppm}$ and $3.32 \mathrm{ppm}$, respectively, corresponding to protons in the propylene oxide (PPO) and ethylene oxide (PEO) moiety of the F127 surfactant. As can be seen, these two spectra reveal differences mainly in terms of peak intensity and width. The CGY-1.5 exhibits lower and narrow peak intensity reported to CGY-1 implying a certain difference in the rigidity and/or organization of the mesostructure of phenolic resin/template composites. This results in good agreement with the observed different textural and structural characteristics of these materials (pore size and geometry, structure symmetry).

Based on these results a synthesis mechanism for the formation of the phenolic resin/pluronic can be proposed. First, it should be considered that glyoxylic acid is an aldehyde with electron-withdrawing substituents which often exist mainly as a hydrate. Thus, the formula for glyoxylic acid can be expressed as $(\mathrm{HO})_{2}-\mathrm{CH}-\mathrm{COOH}$ (eqn (1)).

In the first step, phloroglucinol can react with the glyoxylic acid hydrate, $(\mathrm{HO})_{2}-\mathrm{CH}-\mathrm{COOH}$, by an electrophilic aromatic substitution with the formation of a trihydroxy phenylacetic acid compound. In the next step, the trihydroxy phenylacetic acid further reacts with another phloroglucinol molecule by two possible mechanisms. The first mechanism (eqn (2)) involves an electrophilic aromatic substitution giving rise to carboxylic acid bridges between the benzene rings.

Further elimination of $\mathrm{H}_{2} \mathrm{O}$ by condensation of the carboxylic group with the hydroxyl group induces the creation of lactone bridges (eqn (3)). This was shown by IR and ${ }^{13} \mathrm{C}$ NMR analysis (39.1 ppm).

The second mechanism is based on condensation reactions by the nucleophilic addition-elimination approach (eqn (4)). Taking into consideration the ${ }^{13} \mathrm{C}$ NMR results, the second mechanism seems to occur only in the case of CGY-1.5 resin taking into consideration the presence of $24.7 \mathrm{ppm}$ chemical shift. As the quantity of glyoxylic acid in the reaction mixture is higher for CGY-1.5, the carboxylic groups of trihydroxy phenylacetic acid can condense directly with a hydroxyl group of phloroglucinol with the formation of ester bridges (eqn (4)). The compounds formed can further condensate and longer polymer chains can be formed. It should be mentioned that various possibilities of substitution/condensation reactions in different positions on the phenol ring are possible as a function of experimental conditions. In addition, $\mathrm{H}$-interaction between the functional groups of resols $(-\mathrm{OH},-\mathrm{COOH})$ and the block polymer ether bridges are also present, favoring the self-assembly of ordered mesostructures. Considering these results, it is evident that the present synthesis mechanism is 

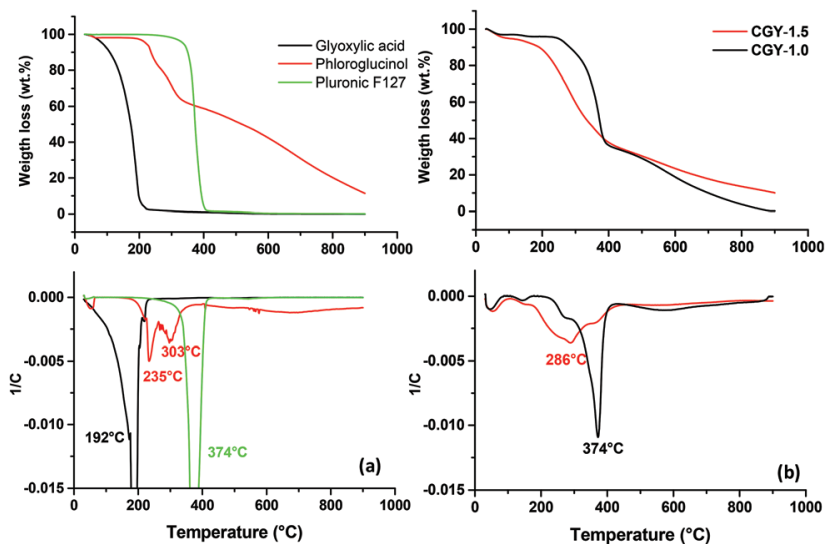

Fig. 7 TGA weight loss and DTG derivative weight loss curves of (a) individual precursors used for the synthesis and (b) phenolic resin polymer CGY-1.0 and CGY-1.5.

much more complex than in the case of classical phenol/ formaldehyde systems where no carboxylic groups are involved.

The IR and NMR results revealed several differences between the CGY-1 and CGY-1.5 resins which could explain partly the different textural and structural features of the derived carbons (Fig. 1 and 2).

However, the thermal decomposition of the resins may also induce modification and this process was studied in detail. The resulting phloroglucinol/glyoxylic acid thermopolymerized at $80{ }^{\circ} \mathrm{C}$ was further carbonized at $380{ }^{\circ} \mathrm{C}$ and $600{ }^{\circ} \mathrm{C}$ to decompose the template with the formation of the mesoporosity.

The as-made CGY- 1 phenolic resin $\left(80^{\circ} \mathrm{C}\right)$ shows two SAXS peaks (Fig. 8a) at $q$ around 0.45 and $0.7 \mathrm{~nm}^{-1}$ which can be indexed as 10 and 11 reflections of an ordered hexagonal mesostructure with a $p 6 m$ symmetry. At this temperature as the template is still not removed, the ordered structure cannot be emphasized by TEM analysis (inset, Fig. 8a), a smooth and dense surface being observed instead.

The carbonization process of phenolic resins heat treated at $80^{\circ} \mathrm{C}$ was followed in situ by TGA analysis performed in nitrogen by heating with a constant heating rate up to $950{ }^{\circ} \mathrm{C}$ (Fig. 7).

For a better understanding, the thermal decomposition of the carbon precursor is also shown. Glyoxylic acid decomposes with a temperature maximum at around $200{ }^{\circ} \mathrm{C}$, phloroglucinol at $300{ }^{\circ} \mathrm{C}$ while the surfactant at $\sim 400{ }^{\circ} \mathrm{C}$.

The phenolic resin CGY-1 decomposes mainly at a temperature similar to that of template removal $\left(\sim 400{ }^{\circ} \mathrm{C}\right)$ while a significantly different decomposition behavior is noticed for CGY-1.5 (synthesized with a higher amount of glyoxylic acid) for which decomposition takes place in a lower temperature interval, comprised between $200{ }^{\circ} \mathrm{C}$ and $400{ }^{\circ} \mathrm{C}$. This can suggest a strong interaction of glyoxylic acid with the template and the phloroglucinol carbon precursor as already emphasized by NMR and IR spectra.

Structural information on the phenolic resin at this stage of the thermal treatment $\left(380^{\circ} \mathrm{C}\right)$ was obtained by SAXS and
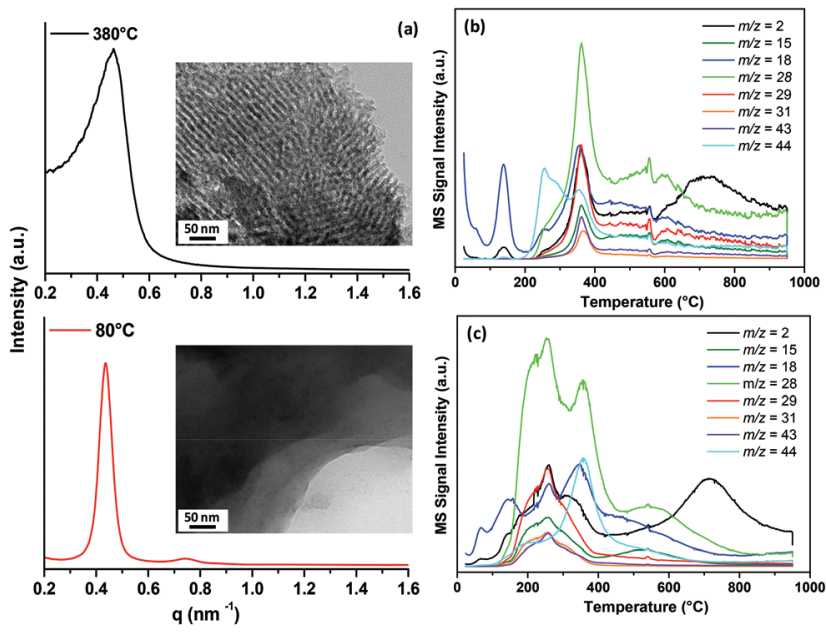

Fig. 8 SAXS patterns (inset: TEM pictures) (a) of the CGY-1 phenolic resin heated at $80{ }^{\circ} \mathrm{C}$ and $380^{\circ} \mathrm{C}$ respectively and TPD-MS desorption curves of CGY-1 (b) and CGY-1.5 (c) phenolic resins/F127 surfactant.

TEM as shown by Fig. 8a. The hexagonal structure is clearly evidenced by the two techniques. In the case of CGY-1 resin, the lattice parameter of the as-prepared CGY-1 $(a=16.6 \mathrm{~nm})$ decreases to $15.6 \mathrm{~nm}(6 \%)$ on heating at $380{ }^{\circ} \mathrm{C}$.

This suggests a small framework shrinkage compared to CGY-1.5 phenolic resin (Fig. S4 and S5†) where 25\% shrinkage is noticed. This is in line with other reports ${ }^{27}$ concerning phenol based resins; however, despite the large framework shrinkage the structural organization is well conserved (Fig. 8a and $\mathrm{S} 4 \dagger$ ).

In addition, for CGY-1 resin, no further significant modification in the lattice parameter is observed when the temperature is increased to $600{ }^{\circ} \mathrm{C}$, while for the CGY-1.5 the cell still contracts by about $15 \%$ (Fig. S5 $\dagger$ ) during this heating step.

As can be observed, for glyoxylic acid and pluronic surfactant a noticeable mass loss occurs and almost no residue is left at the end of the thermal treatment, contrary to phloroglucinol where $\sim 15 \mathrm{wt} \%$ carbon is obtained at $900{ }^{\circ} \mathrm{C}$. This quantity is similar to the one obtained by the decomposition of phenolic resins indicating that phloroglucinol is the carbonyielding component while the pluronic is the structure directing agent and the pore-forming component. Glyoxylic acid is the cross-linker which forms with phloroglucinol a highly cross-linked polymer resin around the template that serves to retain its nanostructure during the decomposition.

Details of the species evolved during the carbonization are provided by TPD-MS analysis. The phenolic resin comprising all these precursors decomposes by releasing several molecules as clearly seen in the TPD-MS spectra (Fig. 8).

The main gas desorption takes place in the same temperature range as observed by TGA analysis (Fig. 7). For CGY-1 (Fig. 8b), in a first step $\left(<100{ }^{\circ} \mathrm{C}\right)$, mainly $\mathrm{H}_{2} \mathrm{O}(\mathrm{m} / \mathrm{z}=18)$ and $\mathrm{H}_{2}(m / z=2)$ are desorbed.

At higher temperature $\left(\sim 250{ }^{\circ} \mathrm{C}\right)$ desorption of $\mathrm{CO}_{2}(\mathrm{~m} / \mathrm{z}=$ 44 ) is noticed being probably related to the decomposition of carboxylic groups $\left(-\mathrm{COO}^{-}\right)$coming from glyoxylic acid. 


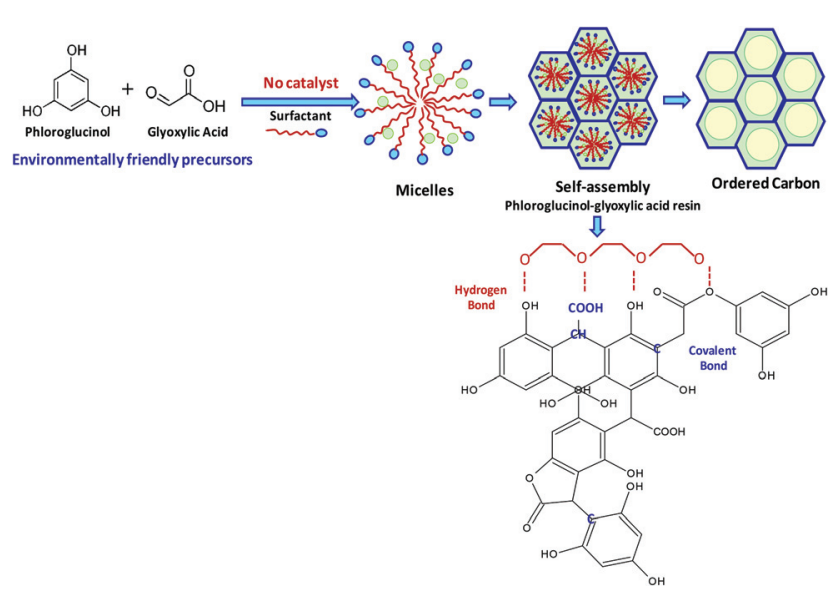

Fig. 9 Schematic representation of the synthesis pathway of ordered carbon using phloroglucinol and glyoxylic acid precursors.

At $\sim 350{ }^{\circ} \mathrm{C}$ an important gas desorption release of $\mathrm{CO}, \mathrm{CO}_{2}$ and methyl, $\mathrm{CH}_{3}-(\mathrm{m} / z=15)$, ethyl, $\mathrm{C}_{2} \mathrm{H}_{5}-(\mathrm{m} / z=29)$, and propyl species, $\mathrm{C}_{3} \mathrm{H}_{7}-(\mathrm{m} / \mathrm{z}=43)$, is observed which corresponds to the decomposition of Pluronic surfactant.

For temperatures higher than $400{ }^{\circ} \mathrm{C}$, desorption of $\mathrm{H}_{2}$, $\mathrm{H}_{2} \mathrm{O}$ and $\mathrm{CO}$ occurs indicating the organization of the carbon by decomposition of oxygenated functional groups and $\mathrm{C}-\mathrm{H}$ bond cleavage. As for the CGY-1.5 sample (Fig. 8c), desorption of $\mathrm{CO}(m / z=28), \mathrm{H}_{2}(m / z=2), \mathrm{H}_{2} \mathrm{O}(m / z=18)$ and ethyl species $(m / z=29)$ is predominant for temperatures inferior to $300{ }^{\circ} \mathrm{C}$, but the presence of methyl and ethyl species $(\mathrm{m} / \mathrm{z}=15$ respectively 43) and ethanol is also noticed. These species are related to the decomposition of pluronic surfactant chains. It should be noted that the decomposition of the pluronic takes place at a lower temperature than $373^{\circ} \mathrm{C}$ suggesting its modification by strong interactions with glyoxylic acid, this behavior not being observed in the case of CGY-1 where smaller glyoxylic acid quantities are used. In addition, at higher temperatures comprised between 300 and $500{ }^{\circ} \mathrm{C}$ simultaneous desorption of $\mathrm{CO}, \mathrm{CO}_{2}$ and water is seen, which could be specific to anhydride decomposition. The presence of anhydrides can be explained by the reaction of two neighboring $-\mathrm{COOH}$ groups with elimination of water. For temperatures higher than $500{ }^{\circ} \mathrm{C}$ mainly $\mathrm{H}_{2}$ desorption occurs due to the cleavage of $\mathrm{C}-\mathrm{H}$ bonding.

Thus, taking into consideration the obtained results, a schematic representation of the ordered carbon synthesis pathway based on phloroglucinol/glyoxylic acid precursors can be illustrated as in Fig. 9.

\section{Conclusions}

A green, simple and efficient approach is demonstrated in this work for the synthesis of ordered carbon powders and films by self-assembly of environmentally friendly phloroglucinol/ glyoxylic acid precursors with a triblock copolymer template in organic medium and without a catalyst. The synthesized materials by tuning the experimental conditions exhibit high surface area and porous volume, defined pore size and architecture (hexagonal 2D, cubic 3D, cage-like) and high thermal stability. The formation mechanism of such structures studied by NMR, TPD-MS and IR proved that both glyoxylic acid functional groups $(-\mathrm{OH},-\mathrm{COOH})$ are involved in the mesostructure formation and play an important role in the formation of various ordered carbons. In summary, the proposed herein synthesis pathway provides a significant step in the improvement of ordered carbon material eco-design by using environmentally friendly precursors, no catalyst, and moreover, a simple, rapid and scalable synthesis approach suitable for industrial applications.

\section{Acknowledgements}

We acknowledge Gautier Schrodj for performing the TGA analysis and Dr Joseph Dentzer for fruitful discussions concerning TPD-MS experiments.

\section{References}

1 R. Ryoo, S. H. Joo and S. Jun, J. Phys. Chem. B, 1999, 103, 7743.

2 J. Lee, S. Han and T. Hyeon, J. Mater. Chem., 2004, 14, 478.

3 T. Kyotani, N. Snobe and A. Tomita, Nature, 1988, 331, 331.

4 H. Nishihara and T. Kyotani, Adv. Mater., 2012, 24, 4473.

5 T.-Y. Ma, L. Liu and Z.-Y. Yuan, Chem. Soc. Rev., 2013, 42, 3977.

6 J. Lee, J. Kim and T. Hyeon, Adv. Mater., 2006, 18, 2073.

7 L. Chuenchom, R. Krahenert and B. M. Smarsly, Soft Matter, 2012, 8, 10801.

8 A. Taguchi and F. Schuth, Microporous Mesoporus Mater., 2005, 77, 1.

9 C. Vix-Guterl, E. Frackowiak, K. Jurewicz, M. Friebe, J. Parmentier and F. Béguin, Carbon, 2005, 43, 1293.

10 J. C. Ndamanisha and L. P. Guo, Anal. Chim. Acta, 2012, 747, 19.

11 Y. Bin, W. Xiaofei, C. Yingxi, H. Jianhan, L. Hongmei and D. Shuguang, Environ. Sci. Technol., 2013, 47, 5474.

12 S. Builes, T. Roussel, C. Matei Ghimbeu, J. Parmentier, R. Gadiou, C. Vix-Guterl and L. Vega, Phys. Chem. Chem. Phys., 2011, 13, 16063.

13 T. W. Kim, P. W. Chung, I. I. Slowing, M. Tsunoda, E. S. Yeung and V. S. Y. Lin, Nano Lett., 2008, 8, 3724.

14 Y. Zhang, H. Wang, C. Gao, X. Li and L. Li, Eur. J. Pharm. Sci., 2013, 49, 864.

15 R. Gadiou, S. E. Saadallah, T. Piquero, P. David, J. Parmentier and C. Vix-Guterl, Microporous Mesoporous Mater., 2005, 79, 121.

16 G. Sun, J. Wang, X. Liu, D. Long, W. Qiao and L. Ling, J. Phys. Chem. C, 2010, 114, 18745.

17 C. Liang, Z. Li and S. Dai, Angew. Chem., Int. Ed., 2008, 47, 3696. 
18 C. Liang and S. Dai, J. Am. Chem. Soc., 2006, 128, 5316.

19 Y. Meng, D. Gu, F. Zhang, Y. Shi, H. Yang, Z. Li, C. Yu, B. Tu and D. Zhao, Angew. Chem., Int. Ed., 2005, 117, 7215.

20 S. Tanaka, N. Nishiyama, Y. Egashira and K. Ueyama, Chem. Commun., 2005, 16, 2125.

21 F. Q. Zhang, Y. Meng, D. Gu, Y. Yan, C. Z. Yu, B. Tu and D. Y. Zhao, J. Am. Chem. Soc., 2005, 127, 13508.

22 J. Wang, C. Xue, Y. Lu, F. Zhang, B. Tu and D. Zhao, Carbon, 2011, 49, 4580.

23 S. Schlienger, A. Graff, A. Celzard and J. Parmentier, Green Chem., 2012, 14, 313.

24 S. Kubo, J. R. White, N. Yoshizawa, M. Antonietti and M. M. Titirici, Chem. Mater., 2011, 23, 4882.

25 R. T. Mayes, C. Tsouris, J. O. Kiggangs Jr., S. M. Mahurin, D. W. DePaoli and S. Dai, J. Mater. Chem., 2010, 20, 8674.

26 C. A. Schneider, W. Rasband, W. S. Sand and K. W. Eliceiri, Nat. Methods, 2012, 9, 671.

27 F. Zhang, Y. Meng, D. Gu, Y. Yan, Z. Chen, T. Bo and D. Zhao, Chem. Mater., 2006, 18, 5279.

28 C. Matei Ghimbeu, C. Decaux, P. Brender, M. Dahbi, D. Lemordant, E. Raymundo-Pinero, M. Anouti, F. Beguin and C. Vix-Guterl, J. Electrochem. Soc., 2013, 160, A1907A1915.

29 C. Matei Ghimbeu, R. Gadiou, J. Dentzer, D. Schwartz and C. Vix-Guterl, Langmuir, 2010, 26, 18824.

30 P. I. Ravikovitch and A. V. Neimark, Langmuir, 2002, 18, 9830.

31 P. I. Ravikovitch and A. V. Neimark, Langmuir, 2002, 18, 1550 .

32 M. Thommes, Chem. Ing. Tech., 2010, 82, 1059.
33 Y. Meng, D. Gu, F. Zhang, Y. Shi, L. Cheng, D. Feng, Z. Wu, Z. Chen, Y. Wan, A. Stein and D. Zhao, Chem. Mater., 2006, 18, 4447.

34 F. Kleitz, T. Czuryszkiewicz, L. A. Solovyov and M. Lindén, Chem. Mater., 2006, 18, 5070.

35 S. Inoue, Y. Hanzawa and K. Kaneko, Langmuir, 1998, 14, 3079.

36 L. Song, D. Feng, N. J. Fredin, K. G. Yager, R. L. Jones, Q. Wu, D. Zhao and B. D. Vogt, ASC Nano, 2010, 4, 189.

37 C. Matei Ghimbeu, J. Le Meins, C. Zlotea, L. Vidal, G. Schrodj, M. Latroche and C. Vix-Guterl, Carbon, 2014, 67, 260.

38 C. Liu, L. Li, H. Song and X. Chen, Chem. Commun., 2007, 757.

39 J. Choma, K. Jedynak, M. Marszewski and M. Jaroniec, Adsorption, 2013, 19, 563.

40 L. Liu, Q.-F. Deng, T.-Y. Ma, X.-Z. Lin, X. X. Hou, Y.-P. Liu and Z.-Y. Yuan, J. Mater. Chem., 2011, 21, 16001.

41 Y. Zhang and Y. Lam, J. Colloid Interface Sci., 2007, 306, 398.

42 C. F. Santa and L. Sierra, J. Braz. Chem. Soc., 2011, 22, 2312.

43 G. Socrates, Infrared and Raman Characteristic Group Frequencies: Tables and Charts, Wiley, 2004.

44 N. E. Marcovich, M. M. Reboredo and M. I. Aranguren, Compos. Interfaces, 1996, 4, 119.

45 I. Poljansek and M. Kranjnc, Acta Chim. Slov., 2005, 52, 238.

46 J. M. Pérez, F. Rodriguez, M. V. Alonso, M. Oliet and J. M. Echeverria, BioResources, 2007, 2, 270. 